\title{
Reduced membrane attack complex formation in umbilical cord blood during Eculizumab treatment of the mother: a case report
}

\author{
Subagini Nagarajah ${ }^{1,2 \dagger}$, Martin Tepel ${ }^{1,2,3^{*}}$, Christian Nielsen ${ }^{4 \dagger}$, Kristian Assing $^{4 \dagger}$, Yaseelan Palarasah ${ }^{5}$, \\ Lise Lotte Torvin Andersen ${ }^{6}$, Lotte Borg Lange ${ }^{1}$ and Claus Bistrup ${ }^{1,3}$
}

\begin{abstract}
Background: Atypical hemolytic uremic syndrome (aHUS) is a disorder of the microvasculature with hemolytic anemia, thrombocytopenia and acute kidney injury. Nowadays, aHUS is successfully treated with eculizumab, a humanized, chimeric lgG2/4 kappa antibody, which binds human complement C5 and blocks generation of C5a and membrane-attack-complex.

Case presentation: A 25-year-old woman with end stage renal disease due to relapsing atypical hemolytic uremic syndrome had a relapse of the disease during pregnancy. She was treated with eculizumab. We measured reduced formation of the membrane-attack complex in newborn's umbilical cord vein blood using the sensitive and specific Palarasah-Nielsen-ELISA.
\end{abstract}

Conclusions: Eculizumab treatment of the mother with end stage renal disease may cause reduced innate immunity which could render newborns more susceptible to infections.

Keywords: Atypical hemolytic uremic syndrome, End-stage renal disease, Pregnancy, Complement, Eculizumab, Umbilical cord vein blood, Membrane-attack complex

\section{Background}

Atypical hemolytic uremic syndrome (aHUS) is a disorder of the microvasculature with hemolytic anemia, thrombocytopenia and acute kidney injury. The pathogenesis of aHUS involves the uncontrolled activation of the alternative complement pathway [1-5]. Nowadays, aHUS is successfully treated with eculizumab [3-7]. Eculizumab is a humanized, chimeric IgG2/4 kappa antibody, which binds human complement $\mathrm{C} 5$ and blocks C5a generation and complement-mediated cell lysis via membrane-attack-complex [6]. However, it is not known

\footnotetext{
* Correspondence: mtepel@health.sdu.dk

†'Subagini Nagarajah, Christian Nielsen and Kristian Assing contributed equally to this work.

'Department of Nephrology, Odense University Hospital, 5000 Odense C, Denmark

${ }^{2}$ Institute of Molecular Medicine, University of Southern Denmark, Odense, Denmark

Full list of author information is available at the end of the article
}

whether the administration of eculizumab in pregnant patients with end-stage renal disease due to aHUS may cause reduced membrane-attack-complex formation also in the fetal circulation. The objective of the present study was to alert clinicians to the effect of therapeutic antibodies in newborns.

For this report we measured the deposition of complement C3 and C9 in the mother's blood, in index newborn's umbilical cord vein blood (obtained after delivery, i.e., $2 \mathrm{~h}$ after the last eculizumab infusion), and in blood 3 weeks after birth we measured deposition of complement C3 and C9 using the Palarasah-NielsenELISA as previously described [8,9]. The sensitive and specific Palarasah-Nielsen-ELISA determines the capacities of three complement pathways using wells precoated with immune complexes, lipopolysaccharides, or mannan, to activate classical, alternative, and lectin pathway, respectively [9]. The deposition of C3 was

(c) The Author(s). 2019 Open Access This article is distributed under the terms of the Creative Commons Attribution 4.0 International License (http://creativecommons.org/licenses/by/4.0/), which permits unrestricted use, distribution, and 
measured using monoclonal anti-human $\mathrm{C} 3$, clone $\mathrm{C} 3$ F1-8, which identifies $\mathrm{C} 3, \mathrm{C} 3 \mathrm{~b}, \mathrm{iC} 3 \mathrm{~b}$ and $\mathrm{C} 3 \mathrm{c}$; and deposition of C9 was measured using anti-human C9 (Bioporto A/S, Gentofte, Denmark), which reacts with the membrane-attack-complex [9]. The advantages of the Palarasah-Nielsen-ELISA had been described [9]. Briefly, $\mathrm{CH} 50$ and AH50 methods are not based on ELISA principle but based on the spectrophotometric measurements of the degree of cell lysis following addition of antibody-sensitized sheep erythrocytes and sheep erythrocytes in solution, respectively. The protocol for the CH50 and AH50 methods is laborious, difficult to standardize, and it is well established that the ELISA methodology is more sensitive compared to these older techniques. Further, and in contrast to the $\mathrm{CH} 50$ and AH50 methods, Palarasah-Nielsen-ELISA is able to distinguish complement capacity between C3and C9 (membrane-attack-complex) -level.

\section{Case presentation}

\section{Clinical findings}

A previously healthy 25 -year-old woman presented to the hospital's emergency department with high blood pressure, hemolytic anemia, thrombocytopenia, and oliguric acute kidney injury. Her blood pressure was 158/101 mmHg. Laboratory data revealed elevated plasma creatinine level, $925 \mu \mathrm{mol} / \mathrm{L}$ (normal range, 45-90), plasma urea, 34.1 $\mathrm{mmol} / \mathrm{L}$ (normal range 2.6-6.4), reduced hemoglobin, 5.5 $\mathrm{mmol} / \mathrm{L}$ (normal range, 7.3-9.5), plasma lactate dehydrogenase, 714 U/L (normal range, 105-205), reduced plasma haptoglobine levels less than $0.08 \mathrm{~g} / \mathrm{L}$ (normal range, 0.351.85), and reduced platelet count, 42 per $\mathrm{nL}$ (normal range, 165-400). A peripheral blood smear showed 6-12 schistocytes per high power field (normal, less than 5). Antinuclear antibodies, antineutrophil cytoplasmic antibodies, anti-glomerular basement membrane antibodies, anti-complement factor $\mathrm{H}$ antibodies, and Hanta virus antibodies were negative. A Disintegrin And Metalloproteinase with a ThromboSpondin type 1 motif, member 13 activity was normal, thus excluding thrombotic thrombocytopenic purpura. Urine analyses showed microscopic hematuria and urinary protein/creatinine ratio was $3.807 \mathrm{mg} / \mathrm{g}$.

Stool culture and multiplex polymerase chain reaction for verotoxin-producing Escherichia coli in stool were negative. A renal biopsy showed 7 glomeruli without fresh thrombotic material, but ischemic damage of glomeruli and tubuli. Vessels showed increased wall thickening without thrombotic material, which may indicate weak thrombotic microangiopathy, and immunofluorescence was negative.

\section{Genetic findings}

Genetic workup revealed no mutations located in the genes for complement factor $\mathrm{H}$, complement factor I, and membrane cofactor protein. The patient had a homozygous deletion of exon 3-6 in the complement factor $\mathrm{H}$ related gene 1 (CFHR1), and a heterozygous deletion of exon 4-6 in the complement factor $\mathrm{H}$ related gene 3 (CFHR3).

\section{Treatment of atypical hemolytic uremic syndrome and chronic kidney disease}

As the case dates back several years, daily plasmapheresis had been started (i.e., plasma exchange of 1.0 plasma volume every day), resulting in attenuation of the hemolytic anemia whereas renal function did not recover. Nowadays administration of eculizumab may be considered [3-7]. Hemodialysis treatment was continued until 20 months later when she received a crossmatch negative AB0-compatible, nonrelated living donor kidney transplant. The immunosuppressive regimen included basiliximab, tacrolimus, and mycophenolate mofetil, and immediate transplant function was unremarkable. However, rising plasma creatinine levels were observed after transplantation together with hemolytic anemia and thrombocytopenia, indicating a relapse of atypical hemolytic uremic syndrome. One biopsy obtained 1 week after transplantation showed 17 glomeruli without thrombotic material, there were no signs for rejection, g0-1v0i1-3 t0-1ah0ptc0. Another biopsy obtained 6 weeks after transplantation showed 7 glomeruli without thrombotic material. Vessels showed increased wall thickening without thrombotic material, and immunofluorescence was positive for $\mathrm{C} 3$ and $\mathrm{C} 4 \mathrm{~d}$. There were no signs for rejection, g1v0i1t0ah1ptc0.

Although tacrolimus was discontinued, whereas prednisolone, plasmapheresis, and eculizumab were started, we observed a progressive deterioration of transplant function and three months later hemodialysis treatment was resumed because of uremic symptoms.

\section{Treatment with eculizumab during pregnancy}

The patient performed home dialysis 6 days per week for $5 \mathrm{~h}$ using a biocompatible membrane. Ten months later, she got pregnant. At gestational age $11+1$ a relapse of the hemolytic anemia and thrombocytopenia was observed (hemoglobin $4.8 \mathrm{mmol} / \mathrm{L}$, haptoglobine levels less than $0.08 \mathrm{~g} / \mathrm{L}$, platelet count 83 per $\mathrm{nL}$ ). Intravenous eculizumab (1200 mg every other week) was started and given throughout pregnancy. The pregnancy was followed closely with repeated ultrasound monitoring growth and fetal blood flows. Intrauterine growth retardation was diagnosed due to suspected fetal distress, a healthy male index baby was delivered by cesarean section in week $34+2$. An eculizumab infusion was given $2 \mathrm{~h}$ before cesarean section. Hemodialysis and eculizumab treatment were continued in the mother and follow ups in both baby and mother after 12 months were uneventful. 
Complement C3 deposition is not affected by eculizumab In the mother's blood, in index newborn's umbilical cord vein blood (obtained after delivery, i.e., $2 \mathrm{~h}$ after the last eculizumab infusion), and in blood three weeks after birth we measured deposition of complement C3 and C9 using the Palarasah-Nielsen-ELISA as previously described $[8,9]$. Fig. 1 shows the capacities of three complement pathways as determined by complement $\mathrm{C} 3$ deposition in the Palarasah-Nielsen-ELISA. Complement C3 deposition was similar in umbilical cord blood from control newborns and index child. The control group consisted of five pre-term (born in gestational week 35-36) boys born to healthy mothers. The lectin pathway activity was abrogated in the index baby as well as the control newborns.

\section{Eculizumab reduces membrane attack complex formation} in the index newborn

Complement C9 deposition which occurs downstream of eculizumab inhibition is shown in Fig. 2. As expected in the mother's blood, complement $\mathrm{C} 9$ deposition induced by activation of the classical pathway was completely abolished (0\% compared to 59 to $130 \%$ in healthy adults) [9]. It should be noted that complement C9 deposition induced by activation of the classical pathway was almost completely abrogated in umbilical cord blood from the index newborn (2\%), whereas newborn controls showed a median of $70 \%$. The control group consisted of five preterm (born in gestational week 35-36) boys born to healthy mothers. Complement $\mathrm{C} 9$ deposition normalized in the index child after 3 weeks. Furthermore, in vitro administration of $100 \mu \mathrm{g} / \mathrm{mL}$ complement factor C5 increased complement $\mathrm{C} 9$ deposition in index child from 2 to $38 \%$. The in vitro effect of eculizumab on complement

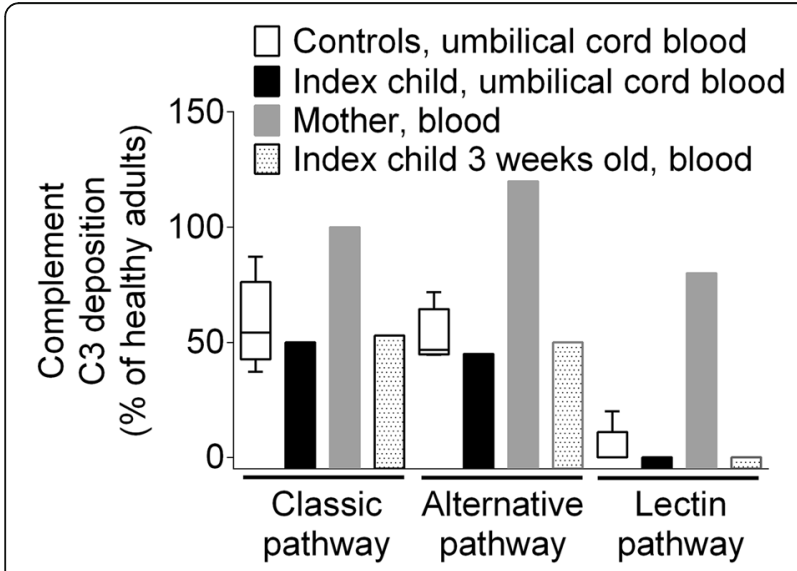

Fig. 1 Complement C3 deposition in index newborn and mother. Complement C3 deposition after activation of the classic, alternative, and lectin pathway in umbilical cord blood from preterm new born controls (box and whiskers plot), umbilical cord blood from the index newborn, in blood from the mother treated with eculizumab, and in blood from the index newborn at 3 weeks. Results are given for the deposition of complement C3 using the Palarasah-Nielsen-ELISA [9]

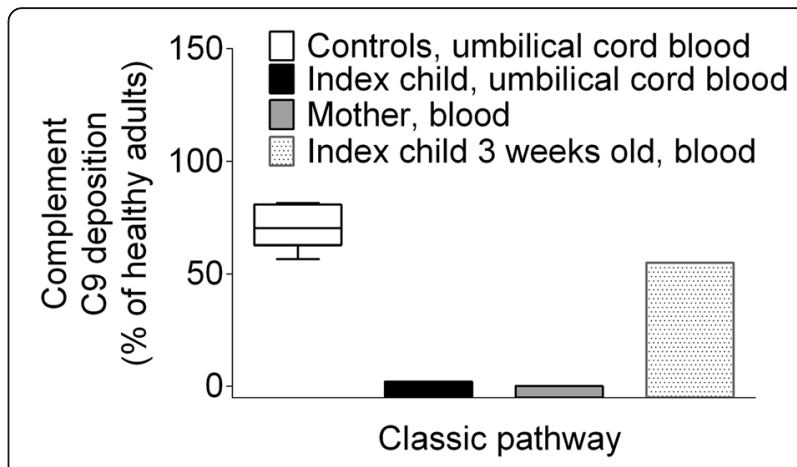

Fig. 2 Complement C9 deposition in index newborn and mother. Complement C9 deposition after activation of the classic pathway in umbilical cord blood from preterm new born controls (box and whiskers plot), umbilical cord blood from the index newborn, in blood from the mother treated with eculizumab, and in blood from the index newborn at 3 weeks. Results are given for the deposition of complement C9 using the Palarasah-Nielsen-ELISA [9]

C9 deposition is depicted in Fig. 3. In-vitro administration of eculizumab to control umbilical cord blood dose-dependently reduced complement $\mathrm{C} 9$ deposition with apparent IC50s ranging from 6 to $10 \mu \mathrm{g} / \mathrm{mL}$.

\section{Discussion and conclusions}

Servais et al. indicated that the administration of eculizumab during pregnancy in three patients with atypical haemolytic uremic syndrome displayed no overt safety issues [10]. However, it should be noted that all babies were born preterm [10]. The index child presented in our study was also born preterm. End-stage renal disease and dialysis may well explain premature birth in our case. However, Segura-Cervantes et al. showed that women with premature preterm rupture of membranes as well as preterm labor had lower soluble C5b-9 complement complexes compared to women during term labor [11]. Human IgG are known to cross the human placental barrier especially in the third trimester [12]. Furthermore, in

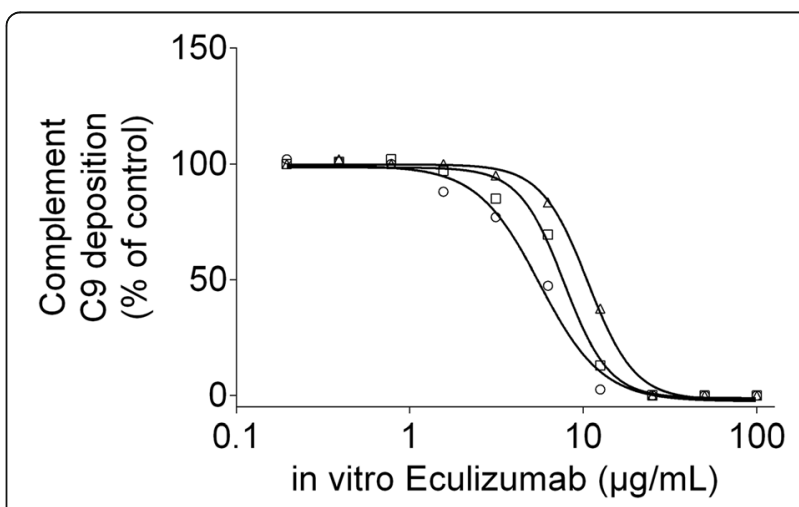

Fig. 3 Dose-dependent effect of eculizumab on complement C9 deposition induced by activation of the classical pathway in umbilical cord blood from controls in vitro 
umbilical cord blood from three mothers with paroxysmal nocturnal hemoglobinuria or antiphospholipid syndrome eculizumab concentrations had been reported [13]. Thus eculizumab may potentially cause terminal complement inhibition in the fetal circulation [14]. This assumption is supported by our present observation. We showed that eculizumab specifically reduces complement C9 deposition, but not complement C3 deposition, in umbilical cord blood from a mother with end-stage renal disease. The impact of eculizumab was supported by the observation that complement $\mathrm{C} 9$ deposition could be rescued invitro by administration of complement $\mathrm{C} 5$. Furthermore, we confirmed that eculizumab may reduce formation of membrane-attack complex in umbilical cord blood from controls in-vitro. The in-vitro effect of antibodies which neutralize complement factors have recently been reported [15]. The fact that eculizumab infusion was given very close to cesarean section may explain why the present results may differ from other cases in the literature.

Genetic studies showed deletions in the gene for CFHR1 and CFHR3 in the mother. According to literature, deletions in CFHR1 and CFHR3 may be associated with atypical hemolytic uremic syndrome [2]. Our case shows that the lectin pathway activity was abrogated in the index baby as well as the control newborns, which is often found in premature children, thus excluding major contamination with blood from the mother, who had normal lectin pathway activity. The present case shows that complement C9 deposition induced by activation of the classical pathway was almost completely abrogated in umbilical cord blood from the index newborn, whereas newborn controls showed a median of $70 \%$. These findings may indicate that the observed effect in the index newborn is more likely due to eculizumab. That is also supported by our finding that complement C9 deposition normalized in the index child after 3 weeks consistent with eculizumab's half-life being of 12-14 days [16].

\section{Limitation of the study}

The present study has several limitations: Additional spectrophotometric assays may be appropriate to confirm the complement findings. Furthermore, genetic findings were not based on next-gen sequencing. Another limitation is that eculizumab titers would have been helpful to strengthen the conclusions.

Taken together we give evidence that eculizumab treatment of the index child's mother reduces the membraneattack-complex formation in the newborn. This may cause reduced innate immunity which could render newborns more susceptible to infections.

\section{Abbreviations}

aHUS: Atypical hemolytic uremic syndrome; CFHR1: Complement factor $\mathrm{H}$ related gene 1; CFHR3: Complement factor $\mathrm{H}$ related gene 3

\section{Acknowledgements}

None.

\section{Authors' contributions}

SN, MT, LLTA, LBL, and CB contributed to patient management. KA organized sampling. CN and YP performed the Palarasah-Nielsen-ELISA-assay. SN, MT, $K A$, and $C B$ designed the study. SN and MT wrote the initial draft of the manuscript. SN, MT, CN, KA, YP, LLTA, and CB contributed to writing of the report. SN, MT, CN, KA, YP, LLTA, LBL, and CB approved the final version. Written consent to publication was obtained.

\section{Authors' information}

None.

\section{Funding}

The authors declare that there was no funding.

Availability of data and materials

All data generated or analyzed during this study are included in this published article.

Ethics approval and consent to participate

Approval was obtained from the regional committee (Data protection agency, Datatilsynet Region Syddanmark, number 17/43602).

\section{Consent for publication}

Written informed consent was obtained from the person to publish information.

\section{Competing interests}

The authors declare that they have no competing interests.

\section{Author details}

${ }^{1}$ Department of Nephrology, Odense University Hospital, 5000 Odense C, Denmark. ${ }^{2}$ Institute of Molecular Medicine, University of Southern Denmark, Odense, Denmark. ${ }^{3}$ Department of Clinical Research, University of Southern Denmark, Odense, Denmark. ${ }^{4}$ Department of Immunology, Odense University Hospital, Odense, Denmark. ${ }^{5}$ Research Unit of Immunology and Microbiology, University of Southern Denmark, Odense, Denmark.

${ }^{6}$ Department of Obstetrics and Gynecology, Odense University Hospital, Odense, Denmark.

Received: 20 August 2018 Accepted: 19 July 2019

Published online: 07 August 2019

References

1. Kavanagh D, Goodship TH, Richards A. Atypical hemolytic uremic syndrome. Semin Nephrol. 2013;33:508-30. https://doi.org/10.1016/j. semnephrol.2013.08.003

2. Zipfel PF, Edey M, Heinen S, Józsi M, Richter $H$, Misselwitz J, Hoppe B, Routledge D, Strain L, Hughes AE, Goodship JA, Licht C, Goodship TH, Skerka C. Deletion of complement factor H-related genes CFHR1 and CFHR3 is associated with atypical hemolytic uremic syndrome. PLoS Genet. 2007;3:e41.

3. Duineveld C, Verhave JC, Berger SP, van de Kar NCAJ, Wetzels JFM. Living donor kidney transplantation in typical hemolytic uremic syndrome: a case series. Am J Kidney Dis. 2017;70:770-7. https://doi. org/10.1053/j.ajkd.2017.06.024.

4. Legendre CM, Campistol JM, Feldkamp T, Remuzzi G, Kincaid JF, Lommelé $\AA$, Wang J, Weekers LE, Sheerin NS. Outcomes of patients with atypical haemolytic uraemic syndrome with native and transplanted kidneys treated with eculizumab: a pooled post hoc analysis. Transpl Int. 2017;30:1275-83. https://doi.org/10.1111/tri.13022.

5. Licht C, Greenbaum LA, Muus P, Babu S, Bedrosian CL, Cohen DJ, Delmas Y, Douglas K, Furman RR, Gaber OA, Goodship T, Herthelius M, Hourmant M, Legendre CM, Remuzzi G, Sheerin N, Trivelli A, Loirat C. Efficacy and safety of eculizumab in atypical hemolytic uremic syndrome from 2-year extensions of phase 2 studies. Kidney Int. 2015;87:1061-73. https://doi.org/1 0.1038/ki.2014.423

6. Wong EK, Kavanagh D. Anticomplement C5 therapy with eculizumab for the treatment of paroxysmal nocturnal hemoglobinuria and atypical 
hemolytic uremic syndrome. Transl Res. 2015;165:306-20. https://doi.org/1 0.1016/j.trsl.2014.10.010.

7. Volokhina E, Wijnsma K, van der Molen R, Roeleveld N, van der Velden T, Goertz J, Sweep F, Brüggemann RJ, Wetzels J, van de Kar N, van den Heuvel L. Eculizumab dosing regimen in atypical HUS: possibilities for individualized treatment. Clin Pharmacol Ther. 2017;102:671-8. https:// doi.org/10.1002/cpt.686.

8. Palarasah Y, Skjodt K, Brandt J, Teisner B, Koch C, Vitved L, Skjoedt MO. Generation of a C3C specific monoclonal antibody and assessment of $\mathrm{C} 3 \mathrm{C}$ as a putative inflammatory marker derived from complement factor C3. J Immunol Methods. 2010;362:142-50. https://doi.org/10.1016/j.jim.2 010.09.024.

9. Palarasah Y, Nielsen C, Sprogøe U, Christensen ML, Lillevang S, Madsen HO, Bygum A, Koch C, Skjodt K, Skjoedt MO. Novel assays to assess the functional capacity of the classical, the alternative and the lectin pathways of the complement system. Clin Exp Immunol. 2011;164:388-95. https://doi. org/10.1111/j.1365-2249.2011.04322.x.

10. Servais A, Devillard N, Frémeaux-Bacchi V, Hummel A, Salomon L, ContinBordes C, Gomer H, Legendre C, Delmas Y. Atypical haemolytic uraemic syndrome and pregnancy: outcome with ongoing eculizumab. Nephrol Dial Transplant. 2016;31:2122-30.

11. Segura-Cervantes E, Mancilla-Ramirez J, Zurita L, Paredes Y, Arredondo JL, Galindo-Sevilla N. Blood SC5b-9 complement levels increase at parturition during term and preterm labor. J Reprod Immunol. 2015;109:24-30. https:// doi.org/10.1016/j.jri.2015.02.008.

12. Malek A. Role of IgG antibodies in association with placental function and immunologic diseases in human pregnancy. Expert Rev Clin Immunol. 2013; 9:235-49. https://doi.org/10.1586/eci.12.99.

13. Hallstensen RF, Bergseth G, Fossc S, Jægera S, Gedde-Dahl T, Holt J, Christiansen D, Laub C, Brekke OL, Armstrong E, Stefanovic V, Andersenc JT, Sandliec I, Mollnes TE. Eculizumab treatment during pregnancy does not affect the complement system activity of the newborn. Immunobiology. 2015;220:452-9.

14. Eculizumab (Soliris) ANNEX I Summary of product characteristics. http:// www.ema.europa.eu/docs/en_GB/document_library/EPAR.Product_ Information/human/000791/WC500054208.pdf.

15. Fukuzawa T, Sampei Z, Haraya K, Ruike Y, Shida-Kawazoe M, Shimizu Y, Gan SW, Irie M, Tsuboi Y, Tai H, Sakiyama T, Sakamoto A, Ishii S, Maeda A, Iwayanagi Y, Shibahara N, Shibuya M, Nakamura G, Nambu T, Hayasaka A, Mimoto F, Okura Y, Hori Y, Habu K, Wada M, Miura T, Tachibana T, Honda K, Tsunoda H, Kitazawa T, Kawabe Y, Igawa T, Hattori K, Nezu J. Long lasting neutralization of C5 by SKY59, a novel recycling antibody, is a potential therapy for complement-mediated diseases. Sci Rep. 2017;7:1080. https:// doi.org/10.1038/s41598-017-01087-7.

16. Soliris [package insert], Cheshire CT. Alexion Pharmaceuticals, Inc; December 2012, Eculizumab. In: DRUGDEX System [Internet database. Greenwood Village: Thomson Reuters (Healthcare) Inc. Updated periodically; 2012.

\section{Publisher's Note}

Springer Nature remains neutral with regard to jurisdictional claims in published maps and institutional affiliations.

Ready to submit your research? Choose BMC and benefit from:

- fast, convenient online submission

- thorough peer review by experienced researchers in your field

- rapid publication on acceptance

- support for research data, including large and complex data types

- gold Open Access which fosters wider collaboration and increased citations

- maximum visibility for your research: over $100 \mathrm{M}$ website views per year

At BMC, research is always in progress.

Learn more biomedcentral.com/submissions 